Phenomenology \& Practice, Volume 12 (2018), No. 2, pp. 5-14.

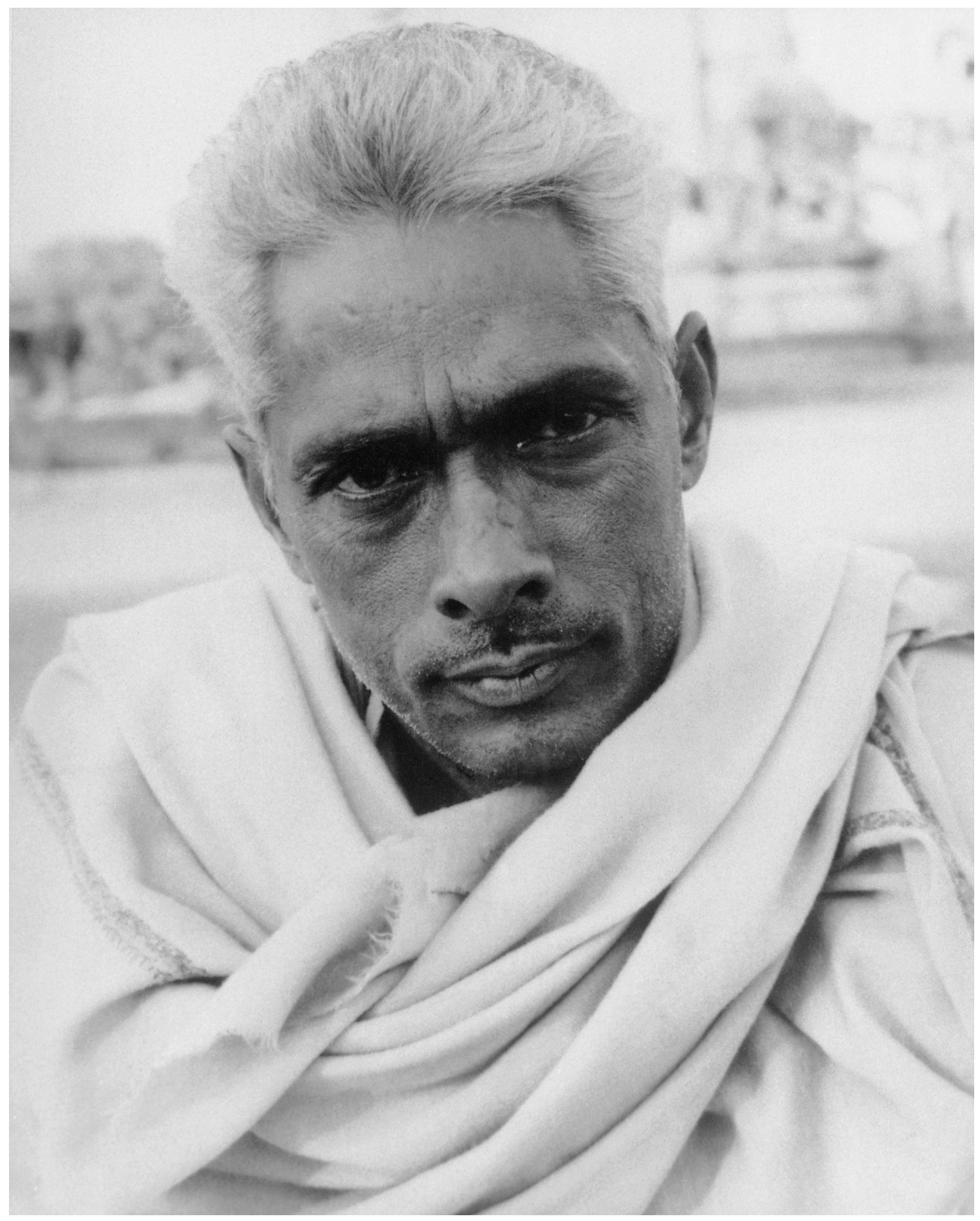




\title{
Cause, Choice, Chance
}

\author{
Alphonso Lingis, Pennsylvania State University \\ allingis@hotmail.com
}

It had started to rain lightly in the Deer Park in Sarnath, where the Buddha had given his first sermon. I took shelter under the huge spreading Bodhi tree, which was grown from a cutting taken from a tree grown from a cutting taken from the Bodhi tree in Bodh Gaya, under which the Buddha attained enlightenment. Someone else had taken shelter there, a man of around 40, dressed in white dhoti and kurta with cream-colored scarf. His presence was very beautiful, composed and gracious; his voice resonant, and he was physically beautiful, too. He said he was an astrologist. I said I would like to hear about his work. He is consulted by people who are troubled - who find that they are unable to cope with their situation. He helps them get in touch with material reality and their bodies. He explains that our bodies are composed of oxygen, carbon, hydrogen, nitrogen, calcium, phosphorous, sulfur, potassium, sodium, chlorine, magnesium, silicon, iron, fluorine, zinc, rubidium, strontium, bromine, lead, copper, aluminum, cadmium, boron, barium, tin, iodine, manganese, nickel, gold, molybdenum, chromium, caesium, cobalt, uranium, beryllium, and radium. He recommended meals of varied and wholesome foods, dusted with ground precious stones, rubies, and sapphires. He then prepares their chart, putting their birth and the cardinal events of their lives in the cosmic map of the most remote heavenly bodies.

There are, he said, necessity, choice, and chance. There is today a rigorous discourse on determinism - the natural sciences, including anatomy, physiology, neurology. He said there is today a rational discourse on decision - ethics and politics. But in the West, there is no longer a reputable discourse on chance; it only survives in the marginalized talk of gamblers and fortunetellers. Each day we attend to the causalities that determine the physical well-being of our bodies and its safety, the causalities that determine the layout of possibilities and obstacles in our environment. We make decisions about the goals we want to pursue and the responsibilities we undertake for the welfare of our children and our community. But all the major events in our lives are due to chance-our birth; a teacher who captivated us and engaged us in mathematics or nursing, music, or football; the person we happened to meet and fell in love with; the job opportunity that abruptly opened; our child who was born or who was autistic or who died; the car crash that crippled us; the tumor that grew silently in our inner organs. There is, he said, an element of chance and risk in every relation with another human being. We never really know what someone might think or might do. We can only trust him or her. Chance is the unpredictable, the incalculable, the incomprehensible, surprise, shock, good, or bad luck.

In any experiment, the formalism of quantum mechanics can predict the possible outcomes and the probability of each of those possible outcomes, but cannot predict a definite outcome for a particular experiment that might have more than one outcome. Statistical mechanics calculates probabilities, that is, chances, in large systems. In the world scrutinized down to the level of atoms, subatomic particles, and radiations, microphysicists accept the Heisenberg uncertainty principle. 
In the universe viewed back to the Big Bang and the subsequent dispersion of clouds of gasses that collected into stars and novae and galaxies, astronomers recognize that the determinisms established for observable and measurable events on this planet no longer apply. Random mutations occur in species, most of which stunt the offspring or make them maladapted to their environment, some of which are beneficial and make the offspring more adaptable, and some of these eventually issue in new strains and new species.

When I think of the chance encounter of this woman with this man-out of the seven billion humans on the planet - of the chance that she pleased him and he her, and of the chance that they disrobed and made love, and then of the infinitesimal chance that out of 200 million spermatozoa repeatedly ejected into her vagina this one met with and got absorbed into this ovum, I can only think that my existence was extremely improbable.

Each gamete contributes 23 chromosomes. They could combine in more than 70 trillion different combinations. This particular combination that I am had but one chance out of 70 trillion to take place. Had any of these other combinations taken place, the child who would have been born would not have been me but someone as different from me as a brother or a sister.

Then I think that in my grandmother's womb the chance that my father was who he is and not someone different was also one in 70 trillion. Likewise, my mother is a staggeringly improbable chance combination, and likewise each of my ancestors.

The more, now, that I study the world, with all the books and laboratories of physicists, chemists, biologists at my disposal, determining, for each event in the world, the conjuncture of disparate causes that brought it about, the less I see that my existence was anywhere programmed in the course of the natural world. Beneath me, behind me, there is nothing that programmed me, required me.

Our enterprising understanding finds itself blocked by unforeseeable chance,, struggles against chance. But my primal recognition of chance is to celebrate the chance of my existence. And thus there is excitement, exhilaration in the recognition of chance events and encounters.

The fact that my facial features are refined or commonplace, that my hair is brown or blond, are effects of chance. I find I have beauty, vivacity, flair, style, dash not through character management but by good luck. As I have the bad luck to be ugly, dull, lumbering, with low vitality and low libido.

As some people have the good fortune to have quick and penetrating minds, there are also people who have a talent for happiness. In the workplace, in everyday situations, in the rain and the snow, they are not dulled and darkened by despondency and laugh a lot. Whereas others, equally endowed with health, self-confidence, intelligence, physical skills always seem to be in neutral or even dull; they have to force themselves to feel happiness.

By a stroke of bad luck, some people have genetic and biochemical predisposition to sociopathology. As there is physical bad luck, there is also moral bad luck. And there is moral good luck, as philosopher Bernard Williams argued. ${ }^{1}$ There are people who are spontaneously generous, people who impulsively leap to help a person in distress at risk to themselves, being brave by nature. People who easily resist peer pressure to go along with shabby and venal behavior. People who do not get overwhelmed with anxiety when a moral decision involves risk to themselves.

Passions are distributed to humans by chance. The passion for truth, which drives great scientists, they say they found it in themselves; it was not really put in them by education. Likewise the passion for justice - awesome in Mohandas Gandhi, Martin Luther King, and Ché Guevara. Passion for adventure, for love. 
Morality exists to counteract fortuna, the good or bad luck that befalls individuals. It aims at an order where goods are distributed according to merit. It excludes chance, caprice, or folly. By postponing the recompense of merit to another world, the rational autonomy Kant celebrated is achieved independently of the accidents of nature and of history.

The compulsively thinking mind, confronting bad and good luck, seeks to find causes and reasons for strokes of luck. These may be inanimate objects, charms, amulets, talismans, tattoos, found or kept on one's person, that bring good luck, and malefic objects and events that are encountered that bring bad. The causes may be willful agents, spirits, gods, or demons. The Roman god Fortuna and the Hindu god Laxshmi were acknowledged to be distributors of luck. The Christian theological concept of Providence attributes all strokes of luck to Divine Plan. Thorton Wilder, in The Bridge of San Luis Rey, recounts that on July 20, 1714 an Inca suspension bridge over a canyon in Peru broke and precipitated five travelers into the gulf below. The Franciscan Brother Juniper witnessed the horror and could not help wondering, "Why did this happen to these five?" He spent the next six years interviewing hundreds of people in an attempt to prove, empirically, scientifically, that Providence had determined that what appeared to common mortals a blow of catastrophic bad luck was exactly the right moment for these people to die. But after six years of interviews, he realized that there was much that was uncertain and much that was not disclosed in all his research. The authorities of the church recognized that and pronounced the work heretical. They ordered his book to be burned, and its author with it.

We know only by raising questions, and everything we discover gives rise to further questions. We pursue knowledge knowing that death will cut short our interrogation before the answers are supplied. We have no idea what significance being a jazz musician, a Southern novelist, a physicist, a nuclear engineer, an American, or a Westerner will have at the end of the century. We will die of AIDS without knowing if a cure will be found a year after our death; we will die of cancer without knowing if the ozone shield hole will be closed or opened ever wider by the advance of industrialization and fossil fuel usage.

Our understanding, in recognizing causalities, and also in recognizing choice and its consequences, locates causes and choice in the linear time of the before and after. Chance events occur without being foreseen in our survey of the causalities of the environment. They occur in a field of time without progression, the time of fate. This time is not given in a separate intuition. It is caught sight of in an event - a birth in all its unforeseeable newness, a death, the annihilation of something unique and irreplaceable.

It happens that a chance event changes not only our circumstances, but also our identity. The economic downturn and three successive years of drought, and he was forced to sell the farm, which had been in the family for three generations. A fall, an injury, and she no longer a dancer; she must build another identity.

The second day of the $15^{\text {th }}$ Conference of the Association for Medical Humanities held in Dartington, Cornwall, we gathered in a small theater. Emily greeted each of us as we entered. She is perhaps 40, wore a big bouffant silver-blond wig, scarlet lipstick, deep eyeshadow, and very long false eyelashes like a cabaret performer, no, drag queen. She sashays vamp provocatively before us. She is wearing a pale blue hospital gown. When we are all seated on the banked rows of seats, she tells of how she became a woman. "I learnt that if you are young and beautiful, and you offer tired, thirsty travellers ripe, juicy grapes they will do whatever you want, so long as you are dressed in green." She dances and says she had a big poster of Patrick Swayze over her bed when she was 14. "I am dangerous. I am inside you. A little kiss, a little bite, creeping through you. My fingers will spread through your body. My tongues will lick from the inside out." She 
tells us these things in raucous slang and with the wanton gestures of a cabaret performer. She is making the turns in her story goofy. She takes off the hospital gown; under it she was wearing another hospital gown but decorated with ribbons, red net petticoats, and French can-can knickers. She undoes the top ribbons and slowly lowers the gown to reveal her flat chest with no nipples. "I got the first of my scars and lost my hair. I lost my left breast. The right one went as well. My ovaries are next on the list. This is how I forgot how to be a woman." She does a provocative dance in the red net petticoats, wig, cosmetics with Patrick Swayze portraying Johnny Castle in Dirty Dancing, possessed with the force to hold him in life. ${ }^{2}$

She leaves, then returns, now no longer in costume, sits with us to listen to us. To a question, she explains that when she was pregnant with her first child they discovered a lump in her left breast. She did not have a full mastectomy, as the anaesthetic would have been too strong for the baby, but a year later she had a recurrence and so had the mastectomy. A further year later they found she had a bracha 1 gene variant that necessitated the second mastectomy and oopherectomy in order to prevent ovarian cancer or another breast cancer. "Who, what am I?" she said. "My body is no longer that of a female," she said. "I am no longer female." She says she never considered a breast reconstruction as she doesn't want to make her cancer invisible or endure further surgery. She says she finds her scars very beautiful.

The recognition of necessity, the recognition of causality or law, is an act of understanding and reason. The recognition of choice is the recognition of possibilities. The recognition of chance is the recognition of something unforeseeable and unpredictable. The recognition of chance is anxiety and exhilaration. Anxiety and fear are the visceral sense of risk, of bad luck, that fills our minds and saturates our nervous sensibility and our musculature, our bodies. Confrontation with chance, with the unpredictable, provokes intense activity in the mind that seeks to understand, but thwarts resolution and decision.

I knew that Owen and Alexa, married when in graduate school, had wanted a child born of their love, but had delayed until both had secured teaching positions. The pregnancy now went well, Alexa noting that in comparison with some of her friends she found she suffered little from morning sickness, heartburn, constipation, or back pain, and even fatigue was minimal. But one night, she was rushed to the hospital and delivered a baby girl. At 24 weeks. They named her Claudia.

The doctor asked Owen and Alexa if they wished Claudia to be on palliative care or put in a neonatal intensive care incubator. Owen found on the Internet statistics for very premature infants, those born after 23 to 25 weeks of gestation.

If they are given palliative care, they will die.

Of those who are given neonatal intensive care $62 \%$ survive; $38 \%$ die.

$27 \%$ will survive without moderate to severe neurodevelopmental impairment.

$38 \%$ will survive with moderate to severe neurodevelopmental impairment, such as

cognitive impairment, cerebral palsy, autism, deafness or blindness, psychosis, bipolar disorder, and/or depression.

$18 \%$ will survive with profound neurodevelopmental impairment.

The Netherlands has a national policy not to put infants born at less than 25 weeks gestation in intensive care.

The doctor explained that they may choose palliative care for their very premature infant, a care aimed at making their short lives as painless and peaceful as possible. He gently but honestly 
told them there is some risk that even with the most conscientious palliative care, the infant may suffer. Owen and Alexa thought with anxiety of day after day visiting their infant doomed to die. They forced themselves to think of how afterwards how they would deal with their decision. To resolve the doubts, misgivings, and desolate memories that may trouble them, they would not have those consoling words (perhaps the only honest consoling words in face of tragedy) "You have done everything you could."

Owen and Alexa recognize that if they choose intensive care, Claudia may be among the $38 \%$ who die in the neonatal intensive care unit. They hope that she will be among the $27 \%$ who survive without moderate to severe neurodevelopmental impairment. How does one weigh a $27 \%$ chance of a healthy life against a $56 \%$ chance of death or profound impairment? They have to assess whether they will be able to bear the financial costs of the lifelong care of Claudia if she turns out to survive with severe neurodevelopmental impairment.

Owen and Alexa cannot not think of their mental and emotional strengths and the professional and social activities that make their lives meaningful to them, which will have to give room to care for a possibly severely impaired child. They wonder if they will want to have another child and think of the impact a severely impaired child will have on the time and resources they devote to another child.

They consult the doctor who delivered Claudia and who had had experience with very premature infants. But they wonder: is he saying what he thinks they would do if they understood all factors involved? Is he taking account of how he thinks they would or could handle the decision and its consequences? Is he saying what he would do if he were the parent?

In this situation with so many factors unknown, they want to hear the experiences and thoughts of other parents who have put a very premature infant in neonatal intensive care. They find that they have to envision the circumstances and character of those other parents and also assess the reasonings that led to their decision.

They meet parents who resolved the uncertainties by deciding on the basis of principles that they have decided are certain and appealed to and reaffirmed to make their decision;--religious principles, for example. They thus delivered themselves from uncertainties and the risks of a decision that they would perhaps later regret. But finding themselves now in a situation where the risks in so important a decision are undecidable make Owen and Alexa see that to take those principles as certain was a decision those parents made in the past. Owen and Alexa have not made such a decision.

The will to open our eyes and our life to the length, breadth, and depth of what comes to pass drives one in extreme pleasure and extreme pain. Without anxiety-without extreme anxiety - chance would not even be perceived. Experience, that inner rending by which we open to the unforeseeable, unpredictable, and unmanipulatable, is painful. Pain undermines our firm stand on familiar ground; every pain is a chance to catch sight of an unknown happiness.

We were taking a drive in the countryside outside of Melbourne. Paul (who is a doctor) was telling me about one of his patients, a young woman of 22, who had an aggressive breast cancer and underwent a double mastectomy and now aggressive radiation and chemotherapy. Her family was comfortable enough, but she had not gone on to college, and recently had been working as a salesperson in a women's clothing boutique.

"One can skim over the world, skim over life," Paul said after a while. "Have a job, just doing each day what there is to be done. Evenings, weekends, talking on the phone with whoever is there. Watching whatever is on television." 
I thought of days, weekends like that. "Like it's one distraction after another," I said. "Like not a distraction from what you chose to do or what is important. Every distraction is a distraction from another distraction."

"Sometimes a serious illness might be the best thing that happens to a person," Paul said hesitantly. "The occasion to work to see what is important, and what is frivolous. What people are important to you, what activities, what pleasures. The occasion to get a sense of oneself as someone distinct who will one day disappear."

The intellect, the reasoning, reckoning intellect tracks down regularities, bases predications on past regularities. This kind of calculative intellect belongs with action, for our initiatives, our projects count on regular patterns in the environment being repeated.

But chance quickens the will. There is excitement, exhilaration in taking chances. Gamblers know this exhilaration, but we also know it in climbing high ladders to paint second floor windows of our house, in speeding on the highway.

Chance is caught sight of in events that befall us and cast before us superabundant gifts. Chance suddenly supplies resources for an undertaking I had not dreamed of; a chance discovery in a laboratory brings me a cure for a malignant condition that had kept me an invalid for twenty years. Chance offers a radiant midwinter day. A chance encounter brings me a lover.

Cameron is the veterinarian whose office is closest to me; I have gone to him with ailing birds and animals. Over the years, I have occasionally met Melissa. When you see Cameron and Melissa together, you see they are in love. The way they look at one another. The way each attentively follows whatever the other is saying. The way their hands easily touch one another. Love, that attachment to him out of dozens, hundreds of men she met over the years, that attachment to her out of all the women he has met.

I discovered that some of the paintings, austere minimalist abstractions, in the veterinary clinic were done by Melissa. Her day job was in a women's shoe store. Cameron was 31 when they met. A dating agency would not have matched them up.

Melissa had brought in a blue-grey barred pigeon that she had rescued from a neighbor's cat. The pigeon had flopped about without being able to take off and fly; what was she was do? The receptionist said, "We do not treat street pigeons". Cameron stepped into the waiting room. He said, "We do not treat street pigeons". Melissa said, "I think he-or she-has a broken wing". Cameron took an X-ray of the wings. Melissa watched him clean the wound and set the little broken bones. "What do I owe you?" Melissa asked. "Nothing”, Cameron said. We do not treat street pigeons. Melissa returned a few days later with the bird for Cameron to clean the wound and change the dressings. Three weeks later Cameron removed the dressings and waved his hands up and down with the pigeon who lifted off and flew around the room. He opened the window and they watched the pigeon fly off to a nearby tree. They went outside to look at the pigeon; it was well. And Cameron and Melissa looked at one another with tenderness. Nothing is more contrary to love than to interrogate, to seek, and to explain that magnetism, that sorcery, to imagine everything in her or his behavior predictable. Nothing is more contrary to love than to exclude strokes of luck, of good luck and therefore to exclude strokes of bad luck too.

Immanuel Kant defines happiness as the abiding state of satisfaction of all our needs and wants. But the English word happiness derived from Old English "hap" (chance, fortune), and meant lucky, favored by fortune. From Greek to Irish, a great majority of the European words for "happy" at first meant "lucky." ${ }^{3}$ See "happen," "happenstance," "perhaps." Surprise is essential to happiness. Happiness is not an enduring good; it is not acquired by character management and 
merit. It is not ruled by the morality of good and evil. It is the state of someone lucky to have found this man or woman to love as no one else can love him or her. It is the state of someone who finds the earth lucky that it has glaciers, sequoias, hummingbirds, and chameleons. And who finds himself lucky to be able to help, to give directions to a stranger on the street, to protect the rain forests, or to safeguard the Ozark big-eared bats.

Moments of supreme happiness - after a laborious trek through forest reaching a cliff over the ocean where radiant colors vibrate the skies like driftings of euphoria, watching comets shimmer across the desert sky, seeing one's turkey parade across the lawn with ten downy chicks, greeting one's grandmother recovered from surgery after a car crash, or receiving one's newborn infant in one's arms. The supreme happiness surges like a gift of chance; no satisfaction achieved through planning and labor is akin.

The sense that the given is given, is a gift of chance, is gratitude. Gratitude is active: it consists in receiving with embracing hands what is given, holding it together, and showing it to, sharing it with others. Happiness is radiant: it gives freely to passersby, to fields and forests, to mountaintops, to the coral reefs, to the depth of the earth, not asking anything in return, not even thanks.

"West Penwith is at the toe of the foot of Cornwall, perched on a massive upwelling of granite. At the rugged north-west edge igneous rock bursts through the hills, exposing high cliffs hovering over windswept beaches." Everything looks random, the shape of the rocks, the foaming crests of the waves, the gusts of wind, the drifting clouds. Sam Bleakley was born in Penzance. When he was five, his father took him with him on surfboards into the waves of the ocean. Sam grew up in love with the ocean.

The wave rises, heavy and thick at the base, light and crisp at the lip as it peaks and throws, breaking free from the anchor that is the deep swell, the incessant tidal motion, the undercurrent, the pulse, the bass-line. As the wave throws bright foam heads, it plays an improvised run against the background mordros, round blue notes against a big beat. Waves are a delicate presence weaved into the sea's force. ${ }^{5}$

Sam grew in love with the sound of the waves. "Nature makes no noise," Thoreaeu wrote. "The howling storm, the rustling leaf, the pattering rain are no disturbance, there is an essential and unexplored harmony in them." The sound of the sea and the movement of the waves are unpredictable, improvisational, but harmonious melody, like free jazz.

Surfing, along with kiteboarding, snowboarding, parachuting, rock climbing, parkour, is considered an adventure or extreme sport, one that has a high level of inherent danger. In the eyes of the public, participants are taken to be thrill-seekers, enjoying a brush with death. Surfing is indeed dangerous, "one slip and your skin is sloughed, your bones ready to show. Even the smallest contact with those electric coral heads will cut, and without quick treatment an infected wound follows." ${ }^{77}$ Burst eardrums cannot be restored. But surfers and other adventure sports enthusiasts find their pleasure in attaining a high level of knowledge of their unpredictable terrains and great skill acquired in situations of extreme difficulty. ${ }^{8}$

Speed is essential to surfing. It is about confidence and rapid decision, positioning, getting in the pocket, but also using the body as a motor making your way into the sweet spot rather than waiting for it to happen. ${ }^{9}$ 
For me, control through style became the goal of surfing. I modeled this on a supposed conversation between bird and fish (or, strictly, mammal) - the equipoise of the hovering kestrel and the grace and playfulness of the dolphin, with its sudden bursts of power, and the balance between keeping the beat and improvising a solo that is central to jazz . . . Control is poise and presence, not force or arrogance; poetics, not persuasion. ${ }^{10}$

The top end of ecstasy in the perfect moment - the tube ride, long hang ten or big weave drop - is a small part of surfing's endless grind and challenge in paddling, duck diving, wipeouts, shark anxieties, bodily wear and tear (because the joints and ligaments give way long before the will) .... This is not masochism, but living the blues, improvising life, making meaning. ${ }^{11}$

The causal determinisms that we track down in our physics and chemistry explain why when we view the sun at the horizon the layers of atmosphere reflect light to us of varying wavelengths, but do not explain why one sunset is more beautiful than another or why a sunset is beautiful. Our botany and biology do not make predictable that the flowers of trilliums are beautiful, that the plumage of pheasants is more beautiful than that of geese, that one Chinese woman but not her sister is beautiful. It is by chance that there is beauty in the world.

See this. See the intricate designs of tiny Alpine and huge tropical flowers, the powdery wings of butterflies and moths, the colors of the three hundred and nineteen species of hummingbirds which are not due to pigment but to the way the crystalline cells of their minuscule feathers reflect the light. See the streaming colors of the coral fish, and the tiny rainbows flashing briefly on bubbles in the surf. See how the setting sun emblazons the skies with unnamable colors different every evening, different every minute of the evening.

\section{Notes}

${ }^{1}$ Bernard Williams, Moral Luck (Cambridge: Cambridge University Press, 1981).

${ }^{2}$ Emily Underwood-Lee, “Titillation." "Dangerous Currents: Risk and Regulation at the Interface of Medicine and the Arts," Association for Medical Humanities Annual Conference 2015, Dartington Hall, Falmouth, Cornwall, England, June 24, 2015.

${ }^{3}$ Online Etymology Dictionary. www.etymonline.com/index.php?term=happy

${ }^{4}$ Sam Bleakley, Surfing Brilliant Corners (Cornwall: Alison Hodge, 2010), 33.

${ }^{5}$ Ibid, 6.

${ }^{6}$ Henry David Thoreau, Journal, vol. 1 (Princeton University Press, 1981), p. 12.

${ }^{7}$ Bleakley, op. cit., 21.

${ }^{8}$ Cf. Kevin Krein, "Nature and Risk in Adventure Sports," in Mike MacNamee, ed., Philosophy, Risk, and Adventure Sports (New York: Routledge, 2007), 84-6. “There is a perverse delight in 
putting oneself in a potentially dangerous situation, knowing that your experience and skill makes you quite safe. To stand with a friend in eerie moonlight at the foot of a vast mountain wall and be certain that you can safely reach the top--that is a wonderful feeling of selfconfidence. It might seem an absurdly pointless thing to do, but to have the nerve to go and try it, just to see if you can, is an affirmation of everything noble in humanity. The task has been rationalised, and carefully weighed, and now you must act and do it right; it is a suspended moment. As you step up on to the first hold or drive the first axe blow you step into a new perspective, a world that is absolutely and cruelly real. The power of it is indescribable, as vital on the first step as it is on the last, at the base or on the summit, and the intensity only gradually fades on your return to the valley." Joe Simpson, This Game of Ghosts (London: Viking, 1994), 118-9.

${ }^{9}$ Bleakley, op. cit., 138.

10 Ibid. 10.

${ }^{11}$ Ibid. 140 . 